\title{
Sex, Gender and Hormones in Dry Eye Disease
}

An Expert Interview with Piera Versura

Ocular Surface Analysis and Translational Research Lab, Alma Mater Studiorum University of Bologna, Bologna, Italy

DOI: https://doi.org/10.17925/EOR.2019.13.2.63

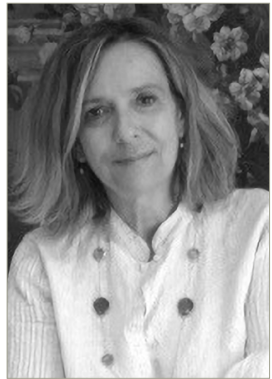

Piera Versura

Piera Versura is Associate Professor at the University of Bologna. She carries out her research in the pathophysiology of the ocular surface, with particular reference to the Dry Eye Disease. She currently focuses her research on the topic ofbiomarkers, predictors of early diagnosis, and indications of therapeutic outcomes in diseases of the ocular surface and on neuroprotection mechanisms. She is engaged in national and international research projects, and is in the Board of Directors of Tear Film and Ocular Surface society (TFOS).

\section{Keywords}

Dry eye deisease, hormones, sex, gender

Disclosure: Piera Versura has nothing to disclose in relation to this article.

Review Process: This is a short expert uinterview and has therefore not undergone the journal's usual peer review process.

Authorship: All named authors meet the International Committee of Medical Journal Editors (ICMJE) criteria

for authorship of this manuscript, take responsibility

for the integrity of the work as a whole, and have given final approval to the version to be published.

Received: 27 November 2019

Published Online: 29 January 2020

Citation: European Ophthalmic Review, 2019;13(2):63-4

Corresponding Author: Piera Versura, Laboratorio Analisi Superficie Oculare e Ricerca Traslazionale, Alma Mater Studiorum Università di Bologna, AOU Policlinico S.Orsola-Malpighi, Pad 1 Via Palagi, 9, I-40138 Bologna, Italy. E: piera.versura@unibo.it

Support: No funding was received in the publication of this article.
$\mathrm{M}$ any ophthalmologists see more women with dry eye disease (DED) than men. This can partly be explained by the fact that more women than men seek professional help for medical conditions, and that DED is more prevalent in elderly people, of whom a higher percentage are female, since women live longer than men. ${ }^{1}$ However, it is increasingly recognised that there are other reasons for the higher incidence of DED in women. ${ }^{2}$ Understanding sex differences in DED is essential for successful disease evaluation and management.In an expert interview, Dr Piera Versura discusses the evidence for the role of sex hormones in the aetiology of DED, and how this evidence may be used to inform future treatment strategies.

\section{Q. What are the differences in the incidence of dry eye disease between men and women?}

Beyond increasing age and certain coexisting conditions (such as autoimmune diseases, in particular Sjögren's syndrome), known risk factors for DED certainly include the female sex. ${ }^{3}$ The prevalence and incidence of DED between sexes vary across studies, but with a higher percentage recorded in women across all ages. In a very recent study that analysed large representative portion of the US population (millions of beneficiaries from the Military Health System, data system ranging from 2003-2015), published in the American Journal of Ophthalmology, it was reported that the ratio of women:men is approximately $3: 1$ in both prevalence and incidence. ${ }^{4}$

\section{Q. What evidence is there that sex hormones play a role in the aetiology of dry eye disease?}

Overall, sex hormones play a major role in the regulation of ocular surface and adnexal tissues, and in the difference in DED prevalence between women and men. Not only are androgens, oestrogens and progestins involved in the mechanism of DED, but also the hypothalamic pituitary hormones, the glucocorticoids, insulin, insulin like growth factor 1 , and thyroid hormones. ${ }^{5}$ Additional interesting, but not yet fully elucidated issues, relate to the roles of the sex chromosome complement (such as the parent-of-origin effects, $X$-inactivation, and genes in the non-recombining region of the $Y$ chromosome), epigenetics (such as microRNA and DNA modifications) and microbiome effects. ${ }^{6}$

\section{Q. How can this evidence be used to inform treatment strategies for dry eye disease?}

This evidence in DED is only just beginning to emerge, and results still in the early stages. However, with regards to the effect of the microbiome on the immune system, an innovative and extremely open field of research for new treatments can be expected in the close future. 


\section{Q. What controversies surround the use of systemic hormone replacement therapy in dry eye in post-menopausal women?}

This is a very interesting question since, despite extensive literature detailing the controversies of hormone replacement therapy (HRT), ${ }^{5}$ a recent systematic literature review revealed that HRT is in fact capable of improving tear production in patients with DED. ${ }^{7}$ These contradictions may be explained by inconsistencies across studies, such as combinations of hormones, posology, method of delivery, age of subjects and many more factors which often make comparison hard or impossible. A more consistent approach to study design is recommended to allow more definite conclusions to be drawn.

\section{Q. What further research is needed?}

One of the purposes of the Subcommittee "Sex, Gender, and Hormones" in the TFOS DEWS II Report, published in 2017, ${ }^{5}$ was to recommend areas for future research, with the aim to advance our understanding of the interrelationships between sex, hormones and DED, and these areas are listed at the end of the report. In a hypothetic time scale of priority the aims are:

- To conduct more epidemiological studies on the prevalence of DED by using both sign and symptom data, and across different regions of the world as data are lacking;

- To assess whether diagnostic tests and management of DED, including therapy, should be different in men and women;

- To communicate clearly about the role of sex and gender influences in the arenas of DED research, patient care, and health and science policy. 口

Donaldson KE. Is dry eye different for women and men? 2018. Available at: www.ophthalmologytimes.com/article/dry-eye-different-women-and-men (accessed 11 November 2019) Stapleton F, Alves M, Bunya VY, et al.TFOS DEWS II Epidemiology Report. Ocul Surf. 2017;15:334-65.

Craig JP, Nichols KK, AKpek EK, et al. TTFOS DEWS II Definition and Classification Report. Ocul Surf. 2017;15:276-83.

Dana R, Bradley IL, Guerin A, et al. Estimated prevalence and incidence of dry eye disease based on coding analysis of a large, all-age United States health care system. Am J Ophthalmol. 2019;202:47-54. Sullivan DA, Rocha EM, Aragona P, et al. TFOS DEWS II Sex, Gender, and Hormones Report. Ocul Surf. 2017;15:284-333.

Alkozi HA, Franco R, Pintor JJ. Epigenetics in the eye: an overview of the most relevant ocular diseases. Front Genet. 2017;8:144.

7. Feng $Y$, Feng G, Peng S, et al. The effect of hormone replacement therapy on dry eye syndrome evaluated with Schirmer test and break-up time. J Ophthalmol. 2015;2015:420302. 